\title{
MATO GROSSO DO SUL - UMA PERCEPÇÃO DA ADMINISTRAÇÃO PÚBLICA
}

\author{
Eliane José de Araújo Gonçalves ${ }^{1}$
}

\section{Introdução}

Mudanças no cenário mundial, ocorridas na última década como evolução da tecnologia da informação, disseminação instantânea dos fatos, volatilidade de capitais, evolução cultural informativa da população e a transparência em fatos públicos, fizeram com que os países que pretendem ser parte dos chamados desenvolvidos, buscassem novas fórmulas de atuação e controle.

No Brasil, particularmente, as mudanças iniciaram a partir da troca do regime militar, em meados dos anos 80 para a democracia. A reviravolta começou em 1990, quanto o então Presidente Fernando Collor de Mello chamou nossos carros de "carroças" e abriu nossa economia para a globalização.

Com o "impechament" do Presidente, abriu-se uma lacuna para a transparência dos fatos outrora escondidos, e que vieram à tona, incentivando a população a exigir respostas satisfatórias a todas as suas necessidades.

O Brasil percebe que o mundo está mudando em uma velocidade tal que, não se adequando a ela, com certeza se colocará cada vez mais distante do sonho da participação do bloco dos países evoluídos. Resultado: crescer ou crescer. Isso implica em preocupações como estar totalmente em sintonia com os grandes países e aberto às economias externas, ser um país para onde os grandes capitais queiram ir e receber 0 aval dos organismos internacionais que estimulam essa prática, e, principalmente ter um governo que atenda a todos esses anseios aliados às perspectivas de crescimento da população.

Atendendo a esses aspectos e anseios da população sobre a questão da transparência dos atos públicos, dentre outros fatores, o Congresso Nacional aprova a Lei de Responsabilidade Fiscal, que exige do Administrador Público, não só responsabilidade sobre os seus atos envolvendo as finanças públicas, como também aumenta as determinações sobre a disponibilidade dessas informações.

Esse fato exige dos Estados, mudanças radicais e necessárias. É como se fosse uma nova lei implícita à natureza da evolução dos tempos; ou se adapta às novas modalidades ou se está fadado a entrar no corredor da falência.

Os Estados brasileiros têm, de uma forma geral, mostrado essa preocupação adequando suas formas de governo, adaptando-se aos exemplos que deram certo no cenário mundial.

O novo governo que se instalou em MS em 1999, adota um novo modelo de gestão. A dificuldade reside no aspecto cultural, onde, por exemplo, os processos com excesso de burocracia estão arraigados de forma a não permitir que novos procedimentos sejam adotados. O entrave da burocracia se dá pela forma como foi utilizada no serviço público. Keinert (2000) ressalta a necessidade de se reconhecer que uma burocracia profissional poderia até tornar-se empecilho ao desenvolvimento nacional. Hoje, porém, é sabido que usada de forma adequada e na medida certa, serve para organizar todo e qualquer estilo de administração.

A adoção da gestão participativa, as dificuldades existentes tanto no aspecto cultural quanto financeiro, as novas exigências legais às quais precisa se adequar exige do governo posturas rijas e de difíceis tomada de decisões, principalmente aliando-se a isso tudo a expectativa da população que espera um governo justo, transparente e que eleve o Estado ao cenário mundial, de modo a permitir o seu desenvolvimento econômico e cultural.

\footnotetext{
${ }^{1}$ Aluna do Curso MBA - Gestão de Organizações Públicas, turma 2000/2001, Universidade Federal de Mato Grosso do Sul, orientada pelos professores e pesquisadores da UFMS, M.sc Caroline Brito Fernandes e Dr. Dario de Oliveira Lima.
} 
Nesse contexto, aparece uma figura de enorme relevância, o Administrador Público, da chamada média gerência. Aquele que não detém em suas mãos todo o poder necessário para tomar as decisões e que, ao mesmo tempo, é responsável pelo andamento dos processos nas organizações públicas.

Outrora, esse gestor ocupava-se em apenas fazer cumprir as determinações, pelo comodismo que a administração burocrática Ihe permitia, não exigindo nada mais que acompanhar os procedimentos pré-estabelecidos, morosos e rotineiros.

Hoje, esse profissional precisa ser um administrador dinâmico, ter a capacidade de trabalhar em grupo e estar tão potencializado quanto os administradores do setor privado, tão informado e potencializado quanto qualquer outro profissional. A sua importância foge do aspecto de acompanhamento e supervisão, é exigido que tome decisões, que esteja apto a responder por processos que sejam pouco producentes e morosos, é responsável pelo desempenho de suas equipes que, em função da reforma do Estado e necessidade de adequação às novas leis de aplicabilidade dos recursos financeiros, encontram-se cada vez mais reduzidas, e principalmente o compromisso que tem com a nova Lei de Responsabilidade Fiscal.

Todos os aspectos acima mencionados nos levam à necessidade de capacitação permanente desse profissional. Levantamos a necessidade de discussão sobre a importância de estabelecimento de perspectiva de uma carreira profissional que o incentive ao crescimento e constante aperfeiçoamento.

Em épocas passadas, quando as regulamentações não dispunham de aspectos punitivos para as más aplicações dos recursos públicos, havia a necessidade de que esses administradores fossem figuras de confiança das autoridades superiores. Levantamos aqui questionamentos acerca do assunto para perguntar, até que ponto ainda se faz necessário a adoção de procedimentos desta natureza, se a Lei de Responsabilidade Fiscal veio para proteger a aplicabilidade de recursos financeiros, e, se a própria dinâmica do cenário administrativo exige que o administrador seja alguém especializado, em condições de atuação rápida e holística?

Levantamos tais questionamentos no intuito de analisar o fator motivacional na carreira do Administrador Público e o seu desempenho, de maneira que o reflexo de sua atuação possa ter a importância necessária e ideal dentro do desenvolvimento das organizações para as quais presta os seus serviços. Utilizamos pesquisas teóricas e qualitativas buscando comparar dados históricos e atuais.

O objetivo deste trabalho é discutir a percepção dos gestores do Estado de Mato Grosso do Sul sobre o novo administrador público. Para tanto, foi feita uma pesquisa junto a trinta e três ocupantes de cargos de média gerência no Poder Executivo do Estado de Mato Grosso do Sul, através de questionário auto-aplicável. A escolha dos elementos da amostra se deu por facilidade de contato nos órgãos públicos.

Desejamos que este trabalho sirva de base às autoridades do Estado, para conhecimento da realidade e necessidades atuais, contribuindo de forma eficaz nas tomadas de decisões para a modernização da administração pública, onde os recursos humanos precisam estar cada dia mais capacitados, potencializados e valorizados.

Apresentamos as características desse gestor no Governo do Estado de Mato Grosso do Sul, e as necessidades inerentes ao profissional da área, de maneira a contribuir com as autoridades do Estado, na formação do seu quadro funcional.

\section{O administrador e as teorias organizacionais}

Responsável pela condução do rumo da organização, a figura do administrador é tão importante quanto a existência da mesma. Podemos até ousar dizer que o administrador é mais importante que a própria organização, pois tem a capacidade de organizar e criar tantas quantas sejam necessárias, enquanto que a organização por si só, não tem como se desenvolver sem a figura humana deste profissional. 
Sendo o processo de trabalhar pessoas e recursos para realizar os objetivos organizacionais, a administração precisa ser eficiente - atingir os objetivos com o mínimo de perda de recursos financeiros, tempo, material e pessoal; e eficaz - atingir os objetivos da organização.O bom administrador deve ter o seu foco profissional voltado tanto para a eficiência, quanto para a eficácia.(BATEMAN/SNEL-1998; DAFT-1999; CHIAVENATO 1982).

Os administradores são classificados como Estratégicos - altos executivos, responsáveis pela administração geral, desenvolvem os planos de forma geral e enfatizam a sobrevivência, o crescimento e eficácia geral da organização; Táticos traduzem os objetivos gerais e planos desenvolvidos pelos administradores estratégicos em objetivos e atividades específicas; -Operacionais - os de níveis inferiores que supervisionam as operações da organização.(BATEMAN/SNEL - 1998; DAFT - 1999; CHIAVENATO - 1982).

Os administradores atuais têm as responsabilidades estratégicas, táticas e operacionais. São pessoas dinâmicas com poder de negociação, capacitadas e habilitadas para tomar decisões. São comprometidas com a missão da organização, com os resultados que ela deve apresentar e para isso são conhecedoras de todas as funções e atividades da organização. Deles depende o sucesso ou o fracasso da organização.

Para tanto, é necessário debater quais as habilidades dos administradores para alcançar o resultado desejado.

Apenas reconhecer e entender as necessidades para bem desempenhar a função da administração não assegura o sucesso da organização. Habilidades técnicas, inter pessoais e de comunicação, conceituais e decisórias, são imprescindíveis para garantir o sucesso da boa administração.(Bateman/Snel - 1998)

As habilidades acima mencionadas serão responsáveis pelo ritmo empreendido ao seu desenvolvimento, a partir da condução do administrador. As habilidades inter pessoais e de comunicação, na administração contemporânea, são vistas como essenciais. Sem a capacidade de envolver pessoas, identificar seus interesses, para saber como motivá-las, saber conduzir o corpo de funcionários, certamente estará fadado ao insucesso. Dividir informações, disseminar conhecimentos, discutir metas, potencializar pessoas e envolvê-las é fundamental para alcançar o sucesso. Os líderes devem estar totalmente envolvidos em todos os departamentos, participando ativamente, conhecer as tarefas desenvolvidas e delegadas a outrem.

Com essa ótica em foco, buscaremos mostrar através de pesquisa realizada junto aos administradores das organizações públicas do Estado de Mato Grosso do Sul, o paralelo que existe entre a realidade e o ideal para a boa administração do Estado.

No decorrer do tempo o papel do administrador se modificou, por exemplo, dentro da perspectiva da evolução das teorias organizacionais.

A Administração ao longo da sua história evolutiva vem exigindo dos administradores, mudanças no sentido de apresentar soluções para os problemas vividos pela sociedade. Os registros desta evolução nos mostram que elas surgem a partir dos meados do século XIX.

$\mathrm{Na}$ verdade pode-se perceber dentro das abordagens administrativas uma divisão entre as chamadas Abordagens Clássicas e Abordagens Contemporâneas, conforme relata Bateman \& Snel (1998). As considerações realizadas sobre as teorias relacionadas abaixo foram feitas com base nas idéias desses dois autores.

A abordagem clássica iniciou-se em meados do século XIX até o inicio da década de 50, é apresentada como Administração Sistemática, que procura construir procedimentos e processos específicos nas operações para assegurar a coordenação dos esforços. 
Em seguida, a Administração Científica, introduzida por Taylor em 1878, defendia a aplicação de métodos científicos para analisar o trabalho e determinar como completar uma tarefa de produção eficientemente.

A Gestão Administrativa surgiu, paralela a administração científica na Europa, em 1916, quando Henry Fayol identificou as cinco funções - Planejar, Organizar, Comandar, Coordenar e Controlar e 14 princípios de administração que vão desde a divisão de trabalho até o espírito de equipe que envolve os funcionários.

A abordagem de Relações Humanas desenvolveu-se no início da década de 30, e visava entender como os processos psicológicos e sociais interagem com a situação de trabalho para influenciar o desempenho.

A abordagem Burocrática, que fecha o bloco das teorias clássicas segundo os autores pesquisados, de Max Weber considerava a burocracia como modelo ideal para a Administração. Objetiva tornar a administração mais eficiente e consistente, de maneira a eliminar a variabilidade de resultados na organização em que os administradores possuíssem diferentes habilidades, experiências e objetivos.

As abordagens contemporâneas iniciam-se com a administração Quantitativa que enfatiza a aplicação de análise quantitativa aos problemas e decisões administrativas. Ajuda o administrador a tomar decisões com técnicas como teorias estatísticas, simulações, previsões, análise de ponto de equilíbrio e outras.

A abordagem de Comportamento Organizacional avalia as atividades administrativas e busca promover o empregado através de um estudo do comportamento do indivíduo, obtendo assim sua maior eficácia.

$\mathrm{Na}$ Teoria dos Sistemas, as organizações são vistas como um sistema aberto que precisam interagir com o ambiente recolhendo os insumos e devolvendo os resultados, com eficiência e eficácia.

$\mathrm{Na}$ Perspectiva Contingencial, as situações de contingências influenciam as estratégias, o que afirma que não existe uma "única melhor maneira" de administrar. 0 administrador precisa aprender a conhecer as contingências para decidir as ações a serem adotadas.

Na gestão da Qualidade Total com o objetivo de satisfazer o cliente utiliza ampla gama de técnicas para atingir alta qualidade em bens e serviços, prevenindo e atingindo zero defeitos. Por outro lado, a chamada Organização Inteligente, aberta a novas idéias, dá oportunidade aos empregados para busca de soluções criativas para os problemas.

Para Chiavenato (1982), a Teoria da Administração surgiu com a "ênfase nas tarefas", a partir da Escola da Administração Científica de Taylor, enriquecida quase que simultaneamente com a "ênfase na estrutura", decorrente da abordagem anatômica de Fayol, a abordagem burocrática de Weber e a abordagem estruturalista, mais recente. A Escola das Relações Humanas surgiu transferindo toda a "ênfase para as pessoas", sendo seguida pela Escola do Comportamento Organizacional e pelo movimento do Desenvolvimento Organizacional (D.O.), evidenciando as reações humanas e democráticas das organizações bem sucedidas. A Teoria dos Sistemas trouxe a "ênfase no ambiente", que chega ao auge com a Teoria da Contingência, e conseqüentemente surgiu a "ênfase na tecnologia".

"Atualmente, a Teoria da Administração considera, simultaneamente, pelo menos estas cinco variáveis reunidas: tarefas, estrutura, pessoas, ambiente e tecnologia. São variáveis interdependentes, e integrantes." "A "era da incerteza" cheia de mudanças e transformações, de turbulência e de instabilidade, que atravessamos no momento, está impondo novos e crescentes desafios para a Administração".(CHIAVENATO - 1982).

Stoner e Freeman (1982), classificam a evolução da Administração como: Escola Clássica - Teoria Científica (Taylor), Teoria Clássica das Organizações (Henry Fayol), Teoria Burocrática (Max Weber); Escola Comportamental - introduzida por Mary Parker Follett e Chester Barnard, onde surgiu o Movimento das Relações Humanas; Escola 
Quantitativa (Pesquisas Operacionais) - onde técnicas matemáticas para a criação de modelos, análises e soluções de problemas de administração; Abordagem Sistêmica que vê a organização como um sistema unificado, composto de partes inter-relacionadas; Abordagem Contingencial (Situacional); e o "Novo Movimento" das Relações Humanas que tem uma visão positiva da natureza humana com o estudo científico das organizações.(STONER/FREEMAN - 1982).

Transpondo esses conceitos para a visão da administração pública, parece-nos que a evolução das abordagens parou na Burocrática. $O$ administrador segue as regras, dá as ordens e exige que sejam cumpridas (Daft-1999). Esta forma de administrar outrora tida como solução para os mais diversos problemas da administração pública, hoje em função da situação deturpada, se contrapõe ao objetivo do seu criador que pregava a precisão, rapidez, ausência de ambigüidade e redução de custos, com otimização destes elementos (Osborne/Gaebler - 1994).

A análise teórica da administração pública inicia-se com os filósofos e ao longo dos tempos diversifica-se com os pensadores contemporâneos que a analisam paralelamente, se não, comparativamente e até em nível de sugestão com a administração privada. Ocorre que as discussões comparativas entre a administração pública e a privada apresentam nuances e variações políticas e partidárias de diversas concepções, inclusive culturais e econômicas.

Em função da necessidade de adequação da administração pública aos moldes da privada, pela própria exigência da evolução dos tempos, surge a proposta da administração gerencial orientada para o cidadão e para obtenção de resultados, descentralizando e incentivando a inovação (Bresser - 1998).

\section{Mudanças estruturais no primeiro mundo.}

Em seu livro Reinventando o Governo, Osborne/Gaebler (1994) apresentam princípios que fundamentaram os governos inovadores nos Estados Unidos. Para os autores Governo é o mecanismo que usamos para tomar decisões coletivas e por outro lado, Empreender é empregar recursos de novas formas, para maximizar a produtividade e eficiência.

A questão da administração pública, ao longo dos anos vem se tornando objeto de estudo de grandes pensadores em função da constante e urgente necessidade de mudança na sua forma de operacionalização.

A velocidade da evolução da tecnologia e informação e conseqüente disseminação do conhecimento exigem um serviço público ágil, com administradores pensantes e dispostos a correr riscos, infelizmente vinculados a uma cultura de manutenção de poder.

Esse mercado exigente e ao mesmo tempo acostumado à morosidade do sistema pesado, produziu profissionais que precisam adequar-se ao momento de transformação desse sistema, que por sua vez está vinculado a normas e procedimentos ditados por leis que devem ser cumpridas.

Peter Drucker (1986,p.22), grande conhecedor da teoria do gerenciamento, afirma: A importante tarefa que está reservada à próxima geração é, portanto, tornar produtivas para o indivíduo, a comunidade e a sociedade, as novas instituições organizadas de nosso novo pluralismo. E isso é o que constitui acima de tudo, o novo papel da administração.

A evolução dos mercados e da sociedade exige que se busque novos meios de executar serviços governamentais, de maneira que se possa aplicar os métodos de tentativas e formas descontínuas.Surge a necessidade de instituições públicas transformadas de burocracias convencionais em organizações inovadoras, flexíveis, respondendo às demandas do público. Os modelos burocráticos criados em uma sociedade onde tudo ocorria muito lentamente eram totalmente satisfatórios. As decisões ocorriam no topo da pirâmide social onde poucos detiam as informações e a maioria usava apenas as mãos para trabalhar.(Osborne/Gaebler - 1994). 
A mudança de postura do mercado exige um serviço público eficiente, flexível e adaptável às necessidades dos clientes. As instituições precisam se adaptar a esse momento de maneira a atender ao cidadão cada vez mais informado e exigente, precisam produzir bens e serviços com alto nível de qualidade e produtividade. O difícil é livrar-se dos antigos conceitos, cultura e normas estabelecidas. Osborne/Gaebler (1994) ressaltam a dificuldade do abandono das antigas idéias.

Osborne/Gaebler (1994) citam experiências de prefeitos e administradores de cidades nos Estados Unidos, utilizando-se de técnicas inovadoras, onde rompem com os sistemas das normas burocráticas, arriscando-se e comprovando os benefícios dessas tentativas. A satisfação da percepção dos resultados alcançados traz à luz declarações como a do prefeito da cidade de Phoenix, após resultados alcançados por seu diretor de Serviços Públicos, Ron Jensen: "Não eram mais burocratas municipais, e nem pessoas com um emprego confortável. Em seu próprio desempenho na competição, viam uma prova de que eram realmente bons" (Osborne/Gaebler - 1994 -p. 82).

É evidente o resultado positivo alcançado pelas experiências ousadas e inovadoras, rompendo com velhos sistemas burocráticos, presos a normas e regulamentos que engessam as ações administrativas.

O avanço administrativo está absolutamente vinculado à liberdade de ação dada aos seus administradores, que são, não apenas potencializados, como também estimulados a buscarem novas formas de gerenciamento das estruturas sob suas responsabilidades, bem como pessoal envolvido. A força que rege tudo que se realiza em nível de administração é a clareza da missão, e a maioria das organizações públicas é orientada, não por sua missão, mas por suas regras e previsões orçamentárias vinculadas. A política de regulamentação das ações no serviço público, através das normas de procedimentos excessivos que estabelecem o que fazer, quando fazer e como fazer impede que o funcionário utilize o seu intelecto e muitas vezes deixa de tomar decisões receoso de uma punição, o que conseqüentemente é um fator de desmotivação. As regras criadas com intenção de proteger o interesse público acabam, porém, trazendoIhe a estagnação, acumulando desperdício e causando danos e prejuízos incomensuráveis aos interesses do cidadão.(Osborne/Gaebler -1994).

A evolução vem provando que o mercado é obrigado a tirar de circulação alguns de seus produtos e serviços que já não são aceitos ou necessários, ao passo que no governo, seus administradores não tem qualquer incentivo para ter o mesmo tipo de procedimento, ao contrário, cria-se novas situações cumulativas que acabam deixando o sistema mais pesado.

A exigência de não se cometer erros na administração pública faz com que o administrador não tenha a oportunidade de se arriscar a grandes acertos.

O sistema administrativo governamental estabelecido através dos já conclamados preceitos das regras, tira do próprio governo a possibilidade de potencializar seus administradores. Desde o estabelecimento das regras orçamentárias, das quais os legisladores não querem abrir mão, por ser uma forma de controlar o "como" os recursos são empregados, não thes são percebidas a necessidade de avaliação da eficiência e eficácia dessa aplicabilidade. Muitas vezes o administrador é obrigado a gastar sem necessidade, para que não perca a possibilidade de ver destinado o mesmo recurso para o exercício seguinte, quando poderia poupá-lo ou empregá-lo de forma adequada e necessária.(Osborne/Gaebler - 1994)

O administrador da iniciativa privada se preocupa em empregar bem e de forma necessária os recursos disponíveis, buscando poupar ao máximo para ficar com saldo para outras aplicações, ao passo que na iniciativa pública isso é impossível. Isso não significa que se deva trabalhar sem um orçamento. Ao contrário, ele é extremamente necessário, porém só será eficaz e eficiente à medida que houver uma flexibilidade e estiver vinculado a uma apuração de resultados. Neste ponto, outra vez se faz necessário 
falar da potencialização do administrador. As regras de aplicação dos recursos disponibilizados através do orçamento devem estar atreladas à necessidade, transparência, eficiência e eficácia na sua aplicabilidade.

A sociedade, outrora passiva, que tudo aceitava ou ainda não reclamava quando da longa espera ou da insatisfação pelo serviço recebido, hoje já não se comporta da mesma maneira. A evolução neste aspecto é gritante, a exigência é expressa através de organizações que buscam seus direitos, exigem que o administrador se explique ou altere sua conduta quando não condiz com as suas expectativas.

É claro que ainda estamos longe do ponto ideal, porém também estamos distante daquela sociedade passiva e submissa à vontade governamental.

A prática do investimento para economizar foi algo largamente utilizado por administradores nos Estados Unidos, desde a área de formação profissional até prestação de serviços públicos que geram receitas.

Práticas como as acima citadas fazem parte da transformação de administradores em empreendedores, incentivando-os a arriscarem, livres para pensar, decidir e agir, otimizando seus recursos e maximizando seus resultados, nunca perdendo de foco a missão de sua instituição, sendo-lhes permitido economizar para novas formas de investimentos e/ou distribuição dos lucros.

A descentralização do poder é a onda propulsora que ocupa o lugar das decisões centralizadas, mantidas nas mãos de poucos. A dificuldade de acesso às informações e lentidão em fazê-las disseminadas dava lugar a essa centralização. Hoje, a velocidade da propagação de informações, melhoria no conhecimento da mão-de-obra disponível e necessidade de decisões rápidas, exige a descentralização do poder.(Osborne/Gaebler1994).

Até mesmo por questão de coerência, a percepção das necessidades básicas de uma organização em servir o seu cliente, está na ponta do processo, onde o serviço é prestado, e nada mais prático e racional que se permitir a participação do funcionário envolvido, no processo decisório.

A hierarquia outrora vertical perde lugar para a horizontal.Não há como manter uma estrutura onde as decisões sejam lentas quando a pressão nas bases exige resposta imediata.

A resistência quanto a essas mudanças é latente nas instituições governamentais, pela força da manutenção do poder. Por outro lado, a pressão na sociedade mais informada e exigente leva o governo a essa realidade. São várias as razões que levam à necessidade da adoção do sistema de descentralização. A primeira e grande vantagem é a flexibilidade que permite a adequação às mudanças de circunstâncias perante 0 mercado totalmente mutável como o atual, dando aos funcionários maior grau de eficiência e comprometimento. "Os empregados aprendem logo uma lição: para beneficiarse, efetivamente, da capacidade intelectual e do conhecimento de trabalhadores pensantes, precisamos dar-Ihes autonomia para que tomem decisões" (Osborne/Gaebler1994-p. 276).

Osborne/Gaebler (1994) fazem uma citação sobre Harlen Cleveland, antigo decano do Instituto Humphrey da Universidade de Minnesota, que escreve um fascinante livro a respeito de como se administrar em uma economia do conhecimento: The Knowledge Executive, onde faz referências à diferença de liderança sobre desinformados, quando o controle era feito de forma vertical e estruturado no comando e controle, enquanto que, liderança sobre informados, para se alcançar os resultados esperados, precisa ser exercida com persuasão e evolvendo ou consultando os que têm alguma participação no processo decisório. 


\section{Reforma do Estado De Mato Grosso do Sul}

A necessidade de reforma do Estado não é assunto novo. Em 28 de outubro de 1936, a Lei de Reajustamento, considerada como primeiro passo para a reforma da administração pública, já trazia em suas entranhas o embrião de uma administração de pessoal organizada. Não surtiu os efeitos esperados, porém teve papel fundamental no processo.(Grilo-1983).

A apresentação premente da necessidade de mudanças radicais e indispensáveis nos rumos da administração pública leva o Governo do Estado de Mato Grosso do Sul a rever toda sua estrutura administrativa.

Isso nos fortalece a necessidade de questionar com mais seriedade o papel do Administrador Público do segundo escalão, principalmente com relação a fatores tais como o preparo, o comprometimento, a conscientização e motivação deste administrador para assumir o papel que lhe é atribuído. A responsabilidade dos rumos da administração do Estado está absolutamente aposta a estes profissionais que, em não estando preparados, que poderão fazer? Pode o Estado continuar fazendo de conta que administração se faz conforme a necessidade aperta? A preocupação com a formação destes profissionais pode continuar relegada à boa vontade da sorte?

E sabido que nada se constrói da noite para o dia. Toda estrutura leva tempo para sua edificação. Todo profissional há que ser construído, envolvido com o sistema para um comprometimento efetivo, e principalmente estimulado pela possibilidade de satisfação de suas necessidades como homem.

A Lei 2.152, de 26 de outubro de 2001, dispõe sobre a reorganização da estrutura básica do Poder Executivo do Estado de Mato Grosso do Sul, e conclama absolutamente a figura do Gestor Público, que passa a ser uma peça chave, imprescindível, não só para as tomadas de decisões, como para direcionar o quadro de funcionários administrativos.

Com o plano de reforma e a estrutura operacional enxuta, é necessário otimizar todos os recursos disponíveis de maneira a atender o cumprimento das metas apostas pelo Governo do Estado.

Há muito tempo era gritante a necessidade de tomadas de decisões da natureza das que foram contempladas com a Reestruturação do Estado. A máquina pública pesada, morosa e antiquada não se adequa ao momento ágil, crescente e exigente de decisões rápidas que o mercado global impõe.

Entretanto, efetivar essas mudanças exige tempo, alteração nos valores. O processo em Mato Grosso do Sul está apenas no inicio. Só o trabalho persistente e crítico permitirá a correção dos erros incorporados à cultura do serviço público e possibilitará a melhoria na vida da população. (Gleisi Helena Hoffam - Secretária de Estado Extraordinária de Reestruturação e Ajuste).

O desenvolvimento da capacidade gerencial dos administradores públicos é peça fundamental para o alcance das metas estipuladas.

É notória a diferença entre o gerenciamento da coisa pública, onde todos os procedimentos são vinculados a leis permissivas e/ou proibitivas e da coisa privada, onde tudo é possível desde que se atinja o objetivo final, que é o lucro financeiro.

Porém não se pode fugir da consciência do conhecimento da forma administrativa privada onde os custos são enxutos, o tempo e recursos otimizados e principalmente a supervalorização dos clientes externos e internos. Para isso, seus administradores são, obrigatoriamente atualizados permanentemente, adquirindo novos conhecimentos, acompanhando a evolução tecnológica e sobre recursos humanos, visando sempre produzir o melhor, no menor tempo, para o seu público alvo. Essa cultura há que ser incorporada ao serviço público.

A funcionalidade do sistema depende dos conhecimentos a ele aplicado, da tomada de consciência do seu valor e principalmente do comprometimento com o resultado. 
Esse tipo de comprometimento só se consegue alcançar com o profissional que tenha um horizonte a ser vislumbrado, que tenha um plano para sua carreira.

A Lei de Reestruturação do Governo do Estado de Mato Grosso do Sul, implanta a Escola de Governo que tem por objetivo a formação de gerentes públicos e capacitação permanente desses profissionais, através do artigo 3o , parágrafo $V$ - "Valorização dos recursos humanos da Administração Pública, por meio de qualificação permanente, traduzida em maiores possibilidades de desenvolvimento pessoal e profissional e na adoção de processos competitivos de seleção, promoção e remuneração".

\section{Metodologia e Análise e discussão dos resultados}

O trabalho de pesquisa foi realizado dentro das secretarias do Poder Executivo do Estado de Mato Grosso do Sul com uma amostra de 50 ocupantes de cargos de média gerência, nos primeiros quinze dias do mês de maio de 2001, através de questionário auto-aplicável, dos quais trinta e três foram devolvidos.Para analisar os dados foi utilizada a estatística descritiva.

Os dados analisados nos mostram as características do administrador atuante no Estado de Mato Grosso do Sul.

Observa-se, que a maioria $(45,46 \%$ - quarenta e cinco vírgula quarenta e seis por cento), encontra-se na faixa entre 40 e 50 anos, conforme mostra a tabela 1 . Outro ponto considerável é que $42,42 \%$ (quarenta e dois vírgula quarenta e dois por cento) dos entrevistados possuem entre 30 a 40 anos.

O fator relevante neste caso está em se considerar que o indivíduo para atuar nesta função é bom que já tenha alguma experiência porque está tratando com gerenciamento de pessoas e situações de decisões.

Tabela 1 - Idade.

\begin{tabular}{|l|c|}
\hline \multicolumn{1}{|c|}{ IDADE } & PERCENTUAL \\
\hline Menor que 20 & $0 \%$ \\
\hline De 20 a 30 & $9,09 \%$ \\
\hline De 31 a 40 & $42,42 \%$ \\
\hline De 41 a 50 & $45,46 \%$ \\
\hline Acima de 50 & $03,03 \%$ \\
\hline & \\
\hline TOTAL & $100,00 \%$ \\
\hline
\end{tabular}

Fonte: dados pesquisados.
Tabela 2 -Nível de Renda Individual

\begin{tabular}{|c|c|}
\hline Item & $\%$ Obtido \\
\hline Até $\mathrm{R} \$ 500,00$ & $3,03 \%$ \\
\hline $\begin{array}{c}\text { De } \mathrm{R} \$ 501,00 \text { a } \mathrm{R} \$ \\
1.000,00\end{array}$ & $12,12 \%$ \\
\hline $\begin{array}{c}\text { De } \mathrm{R} \$ 1.001,00 \text { a } \mathrm{R} \$ \\
2.000,00\end{array}$ & $45,46 \%$ \\
\hline $\begin{array}{c}\text { De } \mathrm{R} \$ 2.001,00 \text { a } \mathrm{R} \$ \\
3.000,00\end{array}$ & $24,24 \%$ \\
\hline Acima de $\mathrm{R} \$$ & $15,15 \%$ \\
$3.000,01$ & \\
\hline Total & $100,00 \%$ \\
\hline
\end{tabular}

Fonte: dados pesquisados

A pesquisa nos mostra que $45,46 \%$ (Quarenta e cinco vírgula quarenta e seis por cento) dos funcionários recebem entre $R \$ 1.001,00$ e $R \$ 2.000,00$. Concomitantemente com a faixa salarial entre $R \$ 2.001,00$ e $R \$ 3.000,00$, temos um percentual de $69.70 \%$ (sessenta e nove vírgula setenta por cento) o que denota que a maioria dos gestores públicos tem uma faixa salarial em torno de 5 a 16 salários mínimos vigentes, portanto, um fator determinante na manutenção de seus cargos e na decisão de seguir na carreira pública (Tabela 2), embora $75,76 \%$ dos gestores declarem que não considera satisfatória a remuneração recebida em função da responsabilidade que lhe é atribuída.

Outro fator preponderante, é que, verificando-se outro item do questionário, perguntados se possuíam outro tipo de trabalho, $75,76 \%$ (setenta e cinco vírgula setenta e seis por cento) não possui, em contrapartida $24,24 \%$ (vinte e quatro vírgula vinte e quatro por cento) declararam ter outro tipo de trabalho, o que comprova que o aumento da renda familiar decorre do trabalho de outras pessoas da família. 
Revista Eletrônica de Ciência Administrativa (RECADM) - ISSN 1677-7387

Faculdade Cenecista de Campo Largo - Coordenação do Curso de Administração v. 1, n. 2, nov./2003 - http://revistas.facecla.com.br/index.php/recadm/

Tabela 3 -Nível de Renda Familiar

\begin{tabular}{|c|c|}
\hline Item & $\%$ Obtido \\
\hline Até $\mathrm{R} \$ 500,00$ & $3,03 \%$ \\
\hline De $\mathrm{R} \$ 501,00$ a $\mathrm{R} \$$ & $6,06 \%$ \\
$1.000,00$ & \\
\hline De $\mathrm{R} \$ 1.001,00$ a $\mathrm{R} \$$ & $24,24 \%$ \\
$2.000,00$ & \\
\hline De $\mathrm{R} \$ 2.001,00$ a $\mathrm{R} \$$ & $27,28 \%$ \\
$3.000,00$ & \\
\hline Acima de $\mathrm{R} \$ 3.000,01$ & $39,39 \%$ \\
\hline Total & $100,00 \%$ \\
\hline
\end{tabular}

Tabela 4-Tempo no serviço público

\begin{tabular}{|c|c|}
\hline Item & $\%$ Obtido \\
\hline Menos de 1 ano & $12,12 \%$ \\
\hline De 1 ano a 3 anos & $21,21 \%$ \\
\hline De 3 anos a 5 anos & $6,06 \%$ \\
\hline Acima de 5 anos & $60,61 \%$ \\
\hline Total & $100,00 \%$ \\
\hline
\end{tabular}

Fonte: dados pesquisados

* O salário mínimo vigente é de $R \$ 181,00$ (cento e oitenta e um reais) a partir de 01/05/2001.

Fonte: dados pesquisados

Levando-se em conta o nível de Renda Familiar (tabela 3) em comparação com o Nível de Renda Individual (tabela 2), percebe-se nitidamente que, a maioria dos gestores públicos possui uma renda complementar. A maioria dos funcionários, 39,39\% (Trinta e nove vírgula trinta e nove por cento), declarou ter uma renda familiar superior a $\mathrm{R} \$$ $3.001,00$ (Três mil e um reais), sendo que $51,52 \%$ são casados.

Como mostra a tabela 4, 60,61\% (sessenta vírgula sessenta e um por cento) dos entrevistados está há mais de 05 anos na iniciativa pública, o que mostra que são pessoas que já têm um razoável conhecimento sobre o serviço público. Denota-se que isto reflete na vida social do funcionário, pois apesar de não ter uma renda satisfatória, $96.97 \%$ (noventa e seis vírgula noventa e sete por cento) declarou possuir bens, aos quais destacamos que destes, 63,63\% (sessenta e três vírgula sessenta e três por cento) são imóveis, ou seja, 39,39\% (trinta e nove vírgula trinta e nove por cento) possuem apartamentos e 24,24 (vinte e quatro vírgula vinte e quatro por cento) possuem casa.

Tabela 5 - Formação Escolar

\begin{tabular}{|c|c|}
\hline Item & $\%$ Obtido \\
\hline Nível Médio Incompleto & $0 \%$ \\
\hline Nível Médio & $9,09 \%$ \\
\hline Nível Superior Incompleto & $12,12 \%$ \\
\hline Nível Superior & $51,52 \%$ \\
\hline $\begin{array}{c}\text { Nível Superior e } \\
\text { Especialização }\end{array}$ & $24,24 \%$ \\
\hline $\begin{array}{c}\text { Nível Superior com Esp. } \\
\text { em Adm. Pública }\end{array}$ & $3,03 \%$ \\
\hline Total & $100,00 \%$ \\
\hline
\end{tabular}

Fonte: dados pesquisados.
Tabela- 6 - Recebe incentivos do Governo do Estado

\begin{tabular}{|c|c|}
\hline Item & $\begin{array}{c}\% \\
\text { Obtido }\end{array}$ \\
\hline $\begin{array}{c}\text { Sim - Recebe } \\
\text { incentivos }\end{array}$ & $33,33 \%$ \\
\hline $\begin{array}{c}\text { Não - Não recebe } \\
\text { incentivos }\end{array}$ & 63,67 \\
\hline Total & $\begin{array}{c}100,00 \\
\%\end{array}$ \\
\hline
\end{tabular}

Fonte: dados pesquisados

De acordo com os resultados, detectou-se que a maioria dos gestores públicos de segundo escalão, $51,52 \%$ (cinqüenta e um vírgula cinqüenta e dois por cento) possui nível superior. Percebe-se um interesse em aperfeiçoamento por duas questões encontradas na pesquisa, pois $24,24 \%$ (vinte e quatro vírgula vinte e quatro por cento) dos profissionais possuem nível superior e Especialização em áreas diversas, como também em outro ponto da pesquisa, $75,76 \%$ (setenta e cinco vírgula setenta e seis por cento), admitiu ter freqüentado um curso de aperfeiçoamento nos últimos 05 anos.

Destaca-se também o pouco aperfeiçoamento específico na gestão pública, já que somente $3,03 \%$ (três vírgula três por cento) possuem especialização em Administração 
Pública. Pode-se afirmar que este fato deve-se à falta de incentivos por parte do governo, como afirmam $63,64 \%$ (sessenta e três vírgula sessenta e quatro por cento) como se pode observar na tabela 06 .

Quanto aos cursos de formação dos gestores públicos, destaca-se Administração e Direito, ambas com 18,18\% (dezoito vírgula dezoito por cento), enquanto outros cursos aparecem com menos freqüência e numa gama bastante variável, como Ciências Econômicas, Ciências Contábeis, Psicologia, Pedagogia, apenas admitindo que a ênfase está na área de humanas.

Chama-se a atenção, nesta pesquisa o quadro que segue:

Tabela- 7 - Opinião sobre a Nova Gestão Pública

\begin{tabular}{|c|c|}
\hline Item & $\%$ Obtido \\
\hline Não conhece & $3,03 \%$ \\
\hline $\begin{array}{c}\text { Tem conhecimentos e não se } \\
\text { aprofundou }\end{array}$ & $15,16 \%$ \\
\hline Tem bons conhecimentos & $9,09 \%$ \\
\hline $\begin{array}{c}\text { Tem bons conhecimentos e } \\
\text { pratica }\end{array}$ & $27,27 \%$ \\
\hline $\begin{array}{c}\text { Tem bons conhecimentos e } \\
\text { não pratica }\end{array}$ & $42,42 \%$ \\
\hline $\begin{array}{c}\text { Tem bons conhecimentos e } \\
\text { pratica com limitações face a } \\
\text { postura da instituição }\end{array}$ & $3,03 \%$ \\
\hline Total & $100,00 \%$ \\
\hline
\end{tabular}

Tabela -8 - Funções que ocupou nos últimos dez anos

\begin{tabular}{|c|c|}
\hline Item & $\%$ Obtido \\
\hline Gestor Público & $33,34 \%$ \\
\hline $\begin{array}{c}\text { Assistente na área } \\
\text { Pública }\end{array}$ & $06.07 \%$ \\
\hline $\begin{array}{c}\text { Servidor Público de } \\
\text { carreira }\end{array}$ & $33,33 \%$ \\
\hline Iniciativa Privada & $27,27 \%$ \\
\hline Total & $100,00 \%$ \\
\hline
\end{tabular}

Fonte: dados pesquisados

A pesquisa acusou, que boa parte dos entrevistados, $42,42 \%$ (quarenta e dois vírgula quarenta e dois por cento) tem bons conhecimentos sobre a Gestão Pública, porém não a pratica.

Fazendo-se um parâmetro com a área de atuação dos Gestores públicos nos últimos dez anos, constata-se que o mesmo percentual, ou seja, 27,27\% (vinte e sete vírgula vinte e sete por cento) vieram da iniciativa privada e declaram ter bons conhecimentos e os praticam (veja tabela 8).

Fazendo-se uma análise das tabelas 08 e 09, percebe-se nitidamente, que existe um interesse nos profissionais da área pública (Gestores Públicos), ou seja, há 10 anos permanecem na área pública, bem como se sentem valorizados pelo governo.

Tabela 9 - Quanto ao sentimento de

Tabela 10 - Quanto à ótica da LRF * valorização pelo Governo do Estado

\begin{tabular}{|c|c|}
\hline Item & $\%$ Obtido \\
\hline Sim - Sinto-me valorizado & $66,67 \%$ \\
\hline $\begin{array}{c}\text { Não - Não me sinto } \\
\text { valorizado }\end{array}$ & $33,33 \%$ \\
\hline Total & $100,00 \%$ \\
\hline
\end{tabular}

Fonte: dados pesquisados

\begin{tabular}{|c|c|}
\hline Item & $\%$ Obtido \\
\hline Justa & $48,49 \%$ \\
\hline Injusta & $3,03 \%$ \\
\hline Ideal & $6,06 \%$ \\
\hline Aplicável & $42,42 \%$ \\
\hline Não Aplicável & $0 \%$ \\
\hline Total & $100,00 \%$ \\
\hline
\end{tabular}

Fonte: dados pesquisados

Quanto à LRF - Lei de Responsabilidade Fiscal, salienta-se o censo de justiça e aplicabilidade da Lei. Somando-se estes dois fatores, temos $90,91 \%$ (noventa vírgula noventa e um por cento) de aceitabilidade, portanto, um bom passo para a implementação e consolidação desta Lei. 
Cabe então uma grande interrogação. Se boa parte se sente valorizado, são profissionais de carreira e conhecem a nova gestão governamental (tabela 6), porque então não a praticam? O que ocorre de fato para o impedimento desta prática?

\section{Conclusão}

As pesquisas realizadas mostraram a evolução da administração nas organizações de uma forma geral. É latente a dificuldade desta evolução nas organizações públicas, em função da cultura com excesso de procedimentos burocráticos nelas instalada.

Por outro lado, o avanço tecnológico, responsável pela rápida disseminação do conhecimento e velocidade com que os fatos se fazem conhecidos em todo mundo, veio exigir que os governos se adequassem a essa evolução sob pena de não se manterem em seus propósitos administrativos.

A evolução cultural, aliada à escassez de recursos, e ainda amparada pela legislação vigente, obrigou os Estados a repensarem suas estruturas e forma de atuação.

Todos estes fatores exigem que os profissionais responsáveis pelo desenvolvimento dos serviços públicos estejam realmente potencializados.

Este artigo discutiu as características necessárias ao administrador público neste período de mudança. Foi feita uma pesquisa junto a uma amostra de gestores públicos atuais. É possível concluir que o administrador público urge por um preparo maior na sua área específica, dada as peculiaridades que a envolve, pois mesmo que haja uma aproximação na forma de atuação das organizações em geral, a administração pública levará mais tempo para adequar-se. Por outro lado, este administrador precisa estar preparado e potencializado de maneira a tomar decisões para que possa otimizar os recursos dos quais dispõem para melhor atender o cidadão.

A evolução da administração nos mostra que o mercado está sempre ditando as formas como as organizações precisam caminhar para se manterem ativas e em condições de sobrevivência. A realidade de não se conseguir ocultar os fatos ocorridos em nenhuma parte do mundo, faz com que essa premente necessidade bata às portas das organizações públicas de maneira contundente, exigindo posturas tais quais as adotadas pelas organizações privadas.

Neste ponto, nos deparamos com o conflito maior. Necessidade evolutiva, agilidade, economicidade, eficiência, eficácia, todos os requisitos para uma organização caminhar de forma que sua produtividade seja maximizada e seu corpo de funcionários estimulados a torna-la cada vez melhor, pois assim estarão participando dos lucros que são transformados em satisfação das suas mais diversas necessidades.

O que vemos nas organizações públicas? Uma estrutura pesada, lenta, marcada há muito pela cultura da burocracia excessiva, que à época da sua criação parecia ser a receita ideal para o desenvolvimento de qualquer organização. A tudo isso soma a peculiaridade da característica monopolística dos serviços oferecidos pelo governo, o que dá ao funcionário a garantia de que o usuário estará sempre ali, à sua espera, sem ter a consciência de que o cidadão é o seu empregador, portanto, o seu cliente.

A análise do administrador de segundo escalão do governo de Mato Grosso do Sul nos mostra um profissional com intenção de evolução e perspectiva de crescimento, embora não tenha sentido incentivo por parte do poder público, enquanto que contraditoriamente a maioria se sente valorizado pelo governo do Estado, mesmo não se sentindo satisfeito com a remuneração percebida.

Cabe neste contexto a sugestão para um estudo mais detalhado acerca desse profissional para um melhor conhecimento de suas necessidades e interesses de maneira que possam ser coadunados aos interesses do Estado. Provado está que para um efetivo crescimento do profissional e da organização, se faz necessário que ambos, funcionário e organização tenham seus interesses atendidos. 
A estrutura do Estado de Mato Grosso do Sul disponibiliza, a Escola de Governo, com a finalidade de preparar profissionais para bem atuarem junto às instituições. É claro que para isso há necessidade de investimentos e um planejamento eficiente para 0 preparo e permanente atualização destes profissionais, bem como o desenvolvimento de um plano de carreira, uma vez que a Lei de Responsabilidade Fiscal protege o Estado e cobra uma postura transparente com eficiência e eficácia.

Levantamos aqui uma discussão acerca da necessidade de continuidade nas atividades e projetos desenvolvidos pelas organizações, o que em muitas situações é interrompido quando da troca de governos, pois trocando o primeiro escalão ocorre a troca da média gerência o que acaba por acarretar diversos níveis de prejuízo para o Estado e cidadãos. A troca de comando do Estado não implica na troca da missão dos governantes, que é administrar os recursos oriundos do cidadão em prol dele próprio.

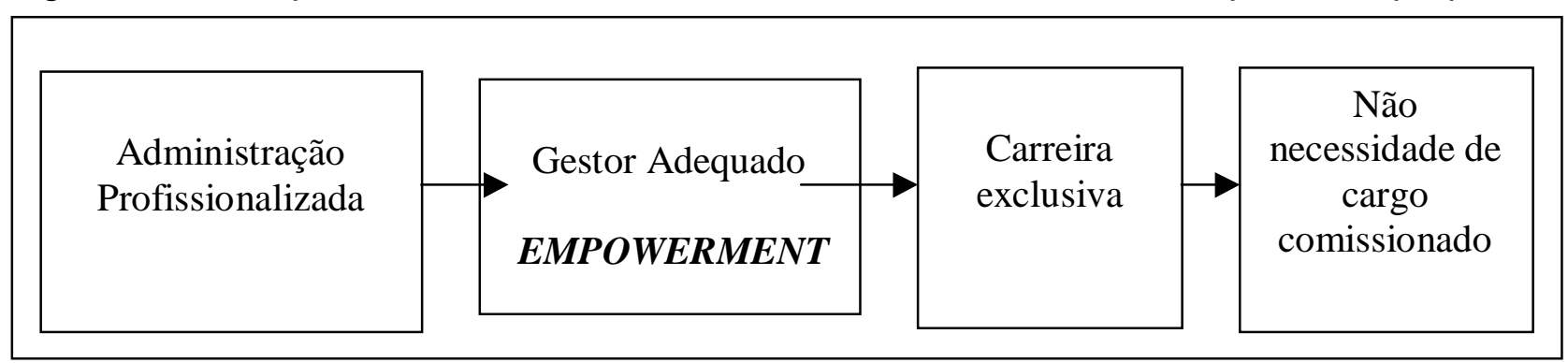

Figura 1

A administração profissionalizada desenvolvida por um gestor dinâmico, apto a tomar decisões e incentivado pela adoção de um plano de carreira exclusiva traz, tanto para esse profissional quanto para o Estado um nível de satisfação adequado, pois atenderá a expectativa de ambos - profissionalismo e otimização de aplicação de recursos financeiros, podendo ser percebido na figura acima.

\section{Bibliografía}

GRILLO, Antonio Nicolló. Recursos Humanos: novos rumos para a Administração Pública. Florianópolis: Editora da UFSC, 1983.

OSBORNE, David \& GAEBLER, Ted. Reinventando o Governo: Como o espírito empreendedor está transformando o setor público. Brasília. Editora MH Comunicações, 1992.

Documento: A Reestruturação Administrativa de Mato Grosso do Sul - Lei 2.152, de 26 de outubro de 2001.

GRAHAM JR., Cole Blease \& HAYS, Steven W. Para Administrar a Organização Pública. Rio de Janeiro: Jorge Zahar, 1994.

Lei Complementar no 101, de 04 de maio d 2000. Lei de Responsabilidade Fiscal

BATEMAN, Thomas S. Administração: Construindo vantagem competitiva.São Paulo: Atlas, 1998.

DRUCKER, Peter F. O Novo papel da Administração, São Paulo: Nova Cultural, 1986.

STONER, James A F. \& FREEMAN, R. Edward. Administração. Rio de Janeiro: LTC Livros Técnicos e Científicos, 1982.

DAFT, Richard L. Administração. Rio de Janeiro: LTC - Livros Técnicos e Científicos, 1999.

PEREIRA, Luiz Carlos Bresser. Reforma do Estado e Administração Pública Geral. Rio de Janeiro: Editora Fundação Getúlio Vargas, 1998.

KEINERT, Tânia Margarete Mezzomo. Administração Pública no Brasil: Crises e Mudanças de Paradigmas. São Paulo: Annablume: Fapesp, 2000.

CHIAVENATO, Idalberto. Administração de Empresas: Uma Abordagem Contingencial. São Paulo: McGraw-Hill do Brasil, 1982. 